\title{
Decentralised Monitoring in Emerging Local Governments: An Analysis of Benefits and Constraining Factors in the Lawra Municipality, Ghana
}

\author{
Bernard Afiik Akanpabadai Akanbang \\ Department of Planning, Simon Diedong Dombo University \\ of Business and Integrated Development Studies \\ bakanbang@uds.edu.gh \\ Cosmas Bekyieriya \\ Department of Governance and Development Management, Simon Diedong \\ Dombo University of Business and Integrated Development Studies \\ Cosmosbekyieriya@yahoo.com \\ DOI//http://dx.doi.org/10.4314/gjds.v17i2.4
}

\begin{abstract}
This paper contributes to the empirical literature on the benefits and constraining factors of monitoring in decentralised governments in emerging democratic governments. Decentralised monitoring has theoretically been recognised as providing comprehensive data for decentralised planning, quality service delivery, enhancing accountability, and assessing development interventions' effectiveness at the local level. However, empirical evidence on its effectiveness in decentralised governance is still evolving. A case study design encompassing the conduct of 12 key informant interviews was used for the study. Findings show that monitoring supports early identification of problems for their quick resolution; enables shared learning; gives voice to community level stakeholders; checks the deviant behaviour of service providers and enhances efficiency in resource use. Inadequate staffing; scrawny knowledge and skills; derisory logistics; noncompliance to budget and calendar for monitoring and uncoordinated arrangements in project implementation constrained decentralised monitoring effectiveness. The evidence gathered support the theoretical arguments for decentralised monitoring and adds to the list of constraining issues in the organisational, human resource and policy factors. The study recommends effervescent advocacy for building monitoring capacity at district level and nurturing
\end{abstract}


political leadership as champions for monitoring in order to get hold of development effectiveness at the local level of governance.

Keywords: Decentralised Governments, Monitoring, Decentralised Monitoring, Benefits, Constraints

\section{INTRODUCTION}

This study analysed the benefits and constraints of decentralised monitoring in emerging democratic local systems as a contribution to anchoring monitoring in developing countries. Monitoring is generally conceived as a continuing function that uses systematic collection of data on specified indicators to provide management and the main stakeholders of an ongoing development intervention with indications of the extent of progress and achievement of objectives in the use of allocated funds (OECD, 2002). Evaluation which often goes with monitoring, on the other hand, refers to the systematic and objective assessment of an on-going or completed project, programme or policy, its design, implementation and results. The aim is to determine the relevance and fulfilment of objectives, development efficiency, effectiveness, impact and sustainability. Evaluation provides information that is credible and useful, enabling the incorporation of lessons learned into the decision making process of both partners and donors (OECD, 2002).

Development actors have given prominence to monitoring in development in direct response to calls for development effectiveness, transparency, accountability, efficiency and quality of services in development governance (Görgens \& Kusek, 2010; Sjöstedt, 2013; Zall, Kusek \& Rist, 2004). Monitoring is an effective and efficient tool for accountability and learning for those involved in development activities to learn from experience and to be more accountable (Umhlaba Development Services, 2011). It provides information on which programmes and projects are not working and those that are working and the reasons (Segone, 2008; Acevedo et al., 2010; Holland \& Ruedin, 2012; Waithera \& Wanyoike, 2015). It also helps those involved with projects to assess if progress is being achieved in line with expectations (Waithera \& Wanyoike, 2015).

For the potential of monitoring to enhance development effectiveness, reinforce mutual accountabilities and realise the Millennium Development Goals (MDGs) now Sustainable Development Goals (SDGs) (African Development Bank, 2006; Cashin, 2012; Akanbang, 2012), development agencies require it as a condition for the provision of concessional assistance and debt relief (Bamberger, Rugh, \& Mabry, 
2011). Decentralised monitoring has become an integral part of poverty reduction programming. It reports on progress of poverty reduction efforts at the district level and is critical in the effective implementation of the district development planning process. It also serves as the main instrument for assessing the extent to which government has performed in its national policy statement and development plan (NDPC, 2014). Monitoring at the decentralised level of governance is relevant for some reasons including: the need for comprehensive data to inform the district planning effort; emphasis on accountability; to determine if development interventions are achieving the needed impact at the local level; and commitment of government to decentralisation process (DISCAP/NDPC, 2004).

In order to harness the potential benefits of monitoring, the Government of Ghana adapted decentralised M\&E as a means of achieving development efficiency and effectiveness in the country. Guidelines to this effect were developed in 2003 by the National Development Planning Commission (NDPC) (Durand, 2004). The NDPC as the agency responsible for coordinating decentralised planning, issues guidelines to regulate the practice of monitoring at the district level. The Upper West Region and the Lawra District were among three few regions and districts in which the decentralised planning guidelines developed by NDPC were first piloted in 2004 under District Capacity Building Project (DISCAP) implemented from 2000 to 2007 (Jackson \& Associates Ltd, 2007).

Research on monitoring in local governance is evolving with many of the work focused on the role of monitoring in local governance (see Maina, 2004; Nelson, 2016; Naidoo, 2011, Ahwoi, 2007); the state and use of monitoring in development programmes (Akanbang, Dugle \& Akaateba, 2019; Akanbang, Yakubu \& Akaateba, 2015; Bamberger, 2008; Holvoet \& Renard, 2006). Significant work has also gone into developing manuals and guidelines for implementing monitoring and evaluation (Zall Kusek \& Rist, 2004). However, not much has gone into examining the operationalisation of monitoring in emerging local government contexts, which is the focus of this study. It seeks to understand from the extant literature and perspective of actors at the implementation and policy level, the benefits as well as the constraining factors of decentralised monitoring. The justification for the study lies in the need for concrete evidence to support decentralised monitoring which has been driven mainly by the World Bank and other external support agencies in the developing world (Mwangi, Nyang'wara \& Kulet, 2015; Akanbang, Dugle \& Yakubu, 2016). Such evidence is essential to leveraging funds and the creation of a learning culture supportive of decentralised monitoring in the developing world. The paper discusses the roles and constraining factors in decentralised monitoring 
as basis for interpreting and discussing the results in section four. The context within which the study was conducted is presented as part of the methods section in order to provide insight into the study. The conclusion presents the take home message of the study and recommendations.

\section{DECENTRALISED MONITORING IN LOCAL GOVERNANCE - BENEFITS AND CONSTRAINING FACTORS}

According to the World Health Organisation (WHO) (2006), decentralised monitoring focuses on improving district-level capacity for data collection, analysis and use in their service programmes. District level monitoring collects and uses information to improve management functions. The district monitoring systems should encompass community and other stakeholders and be guided by participatory basic leadership to guarantee local benefits and ownership. In this study, we operationalise decentralised monitoring as a monitoring system operational at the local government level in which key stakeholders are actively involved in the key processes of monitoring.

Massuanganhe (2005) proposed some objectives of monitoring at the district level. These include: making sure that projects are implemented as scheduled; projects are of good quality and project inputs are utilised well. Decentralised monitoring according to Ahwoi (2007) and Massuanganhe (2005) should be participatory in order to reflect community needs and motivate individuals' enthusiasm for its usage since it is at the community level that projects are operational. A good decentralised monitoring system adds to organisational learning and information sharing by promoting reflection and sharing of knowledge and lessons from the implementation of projects/programmes (International Federation of Red Cross and Red Crescent Societies (IFRC), 2011; Carvil \& Sohail, 2007 cited in Mohamednoor, 2017). It facilitates across learning (Morris \& Lawrence, 2010) and exposes faults and proposes pathways for local authorities to learn and advance and improve upon their policies and practices (Gudda, 2011). Learning is defined as gaining new knowledge, behaviours, skills, values, preferences or understanding and being able to synthesis different kinds of data (Kusters et al., 2011).

\section{Factors Affecting Decentralised Monitoring}

Figure 1 provides a conceptual framework for analysing the benefits and constraining factors of decentralised monitoring in emerging democratic local government systems. 


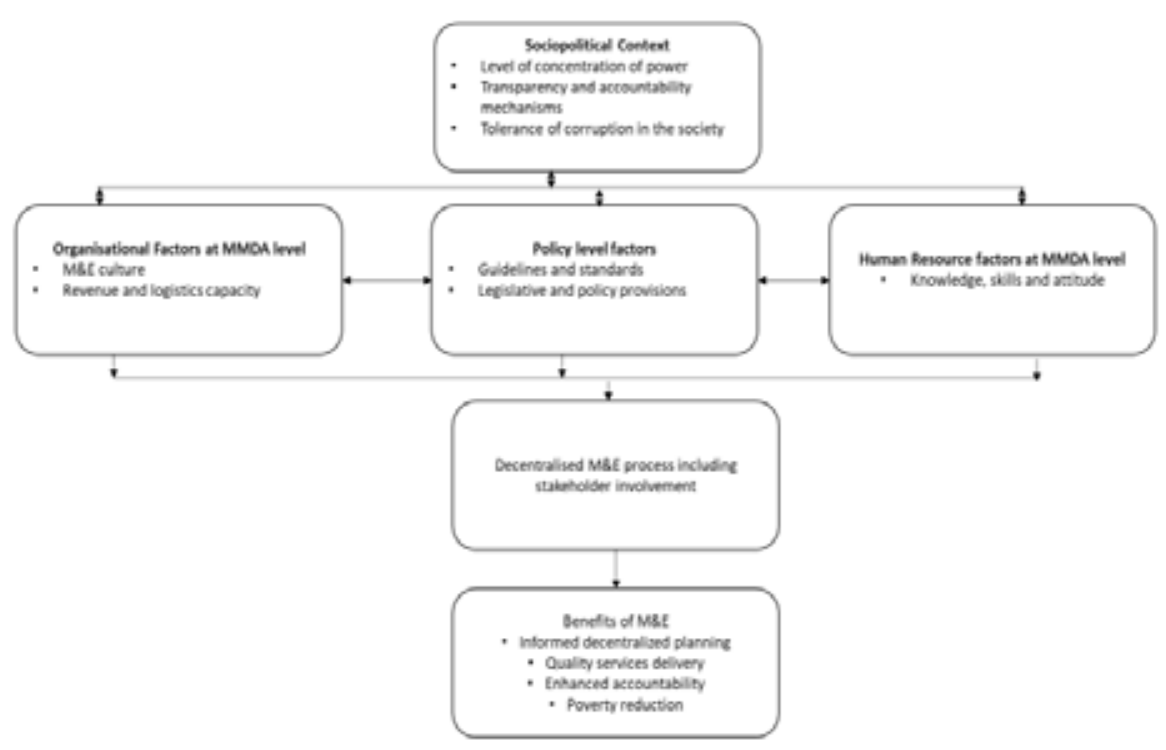

\section{Figure 1: Conceptual framework}

Source: Authors' construct, 2018.

As depicted in Figure 1, the effectiveness of a decentralised monitoring is influenced by the interaction between policy level factors, organisational factors, human resource factors and wider socio-political context factors. These factors are either enablers or constraints to the decentralised monitoring process. Degroff and Cargo (2009) identified socio-political context as a factor affecting successful implementation of interventions. The socio-political factors relate to weaknesses in the accountability mechanisms in place to control discretionary use of power and corruption in local government systems. The policy factors contain the laws and guidelines that provide either the enabling or challenging environment for the practice of monitoring at the decentralised level. Callistus and Clinton (2016), Oloo (2011) and Kerongo et al. (2013) noted unclear institutional framework for conducting monitoring and weak coordination among agencies as challenges of monitoring implementation. Bamberger (1989) cited in Majola (2014) observed difficulties as: centralisation of monitoring systems making them alienable to government control as well as focusing on compliance with national standards as against project effectiveness; limited buy-in of monitoring by government 
departments resulting in little attention to the quality of monitoring; failure to recognise the significant partners required for monitoring leading to a misconception of the utilisation and reasons for monitoring data; view of monitoring practice as the exclusive preserve of the monitoring professional; and monitoring is perceived as a threat by project managers and once in a while hesitant to incorporate and submit progress reports of projects and to utilise assessment proposals to improve project execution.

The organisational factors as reflected in Figure 1, refer to organisational issues as learning culture, decision making processes, learning processes, financial resource availability among others, which can influence how organisational members and subnational stakeholders perceive and operationalise monitoring. Financial commitment is a critical determinant when it comes to local people's involvement in monitoring processes as money is required in organising meetings, field visits, training to enhance the staff as well as local people's skills and knowledge to implement monitoring at the district level (Callistus \& Clinton, 2016; Jili \& Mthethwa, 2016; Mark, 2007). In cases where financial provision has been made for monitoring, provision is seldom made for systematic baseline and subsequent beneficiaries surveys (IFAD, 2008) resulting in significant underestimated of monitoring budgets (IFAD, 2008; Oloo, 2011; Kerongo et al., 2013). It has been noted that where limited budgets have been made for monitoring, releasing the funds for implementation is yet another headache (Tengan \& Aigbavboa, 2016). Kamau and Mohamed (2015) note human resource as a factor affecting decentralised monitoring.

The human resource factors refer to the knowledge, skills, attitudes, motivations and incentives required for effective decentralised monitoring. Mugambi and Kanda (2013) found deficiency of understanding of the significance of and purposes of monitoring, the monitoring process; poor skills on results-based monitoring which have the effect of affecting the quality of the outcomes of monitoring systems. Oloo (2011), Kerongo et al. (2013), Mushori (2015), Toscano (2013) and Jili and Mthethwa (2016) also observed limited training and technical skills deficiencies in monitoring of people tasked with monitoring and evaluation activities at the local level as a factor affecting monitoring implementation. Specifically, technical skills in monitoring design, particularly the logical framework design, setting of indicators: data collection instruments design, which includes questionnaires and conducting focus group discussion have been noted as an area of need by monitoring personnel (Hughes d'Aeth, 2002; Kamau \& Mohamed, 2015; Callistus \& Clinton, 2016). The effect of deficiencies in such skills according to Gillian et al. (2003) cited in Mark 
(2007) is that decision making is established on intuition rather than on strong evidence. Rajalahti, Woelcke and Pehu (2005) note lack of national capacity for monitoring while Mwangi, Nyang'wara and Kulet (2013) observed technical capacity as challenges affecting the implementation of monitoring. Consequently, Mibey (2011) cited in Nyamongo (2017) recommends capacity enhancement as a key component of monitoring design and implementation. The implementation of monitoring by stakeholders deficient in knowledge and skills in it makes it to become tedious, expensive and irrelevant (Nabris, 2002). As noted by Weyrauch and Langou (2011), the skills of people involved in conducting monitoring activities determine how they would involve their stakeholders and communicate findings to the stakeholders and ultimately the effect of monitoring on project results.

The monitoring process determines its outcomes. At the district level, the monitoring process includes formation of the monitoring team; preparing monitoring plans; setting of indicators; work plan and calendar preparation; field visits; data collection, analysis and validation; report writing; and communication of monitoring results and use of the results (NDPC, 2014).

\section{STUDY CONTEXT AND METHODOLOGY}

\section{Study Context}

Figure 2 presents a map of the study in national and regional contexts. The study is anchored on the framework for decentralised monitoring in Ghana which is integrated in the decentralised development planning system. Section 1(2) of the National Development Planning System Act, 1994 (Act 480) stipulates that the decentralised national development planning system shall comprise MMDAs at the district level, Regional Co-ordinating Councils (RCC) at the regional level and sector agencies, Ministries and the NDPC at the national level. The NDPC as the coordinator of the decentralised development planning system among other functions develops planning and monitoring guidelines for local authorities (MMDAs). The RCCs have the functions of coordinating, monitoring, evaluating and harmonising of development activities at the regional level. Specifically, they provide among others: guidance to the districts in the development and execution of their monitoring plans; evaluate, recommend and support capacity building and other monitoring requirements of the district assemblies. At the district level, the District Planning Coordinating Unit (DPCU) has been established to execute planning, programming, monitoring, evaluating and co-ordinating functions. 


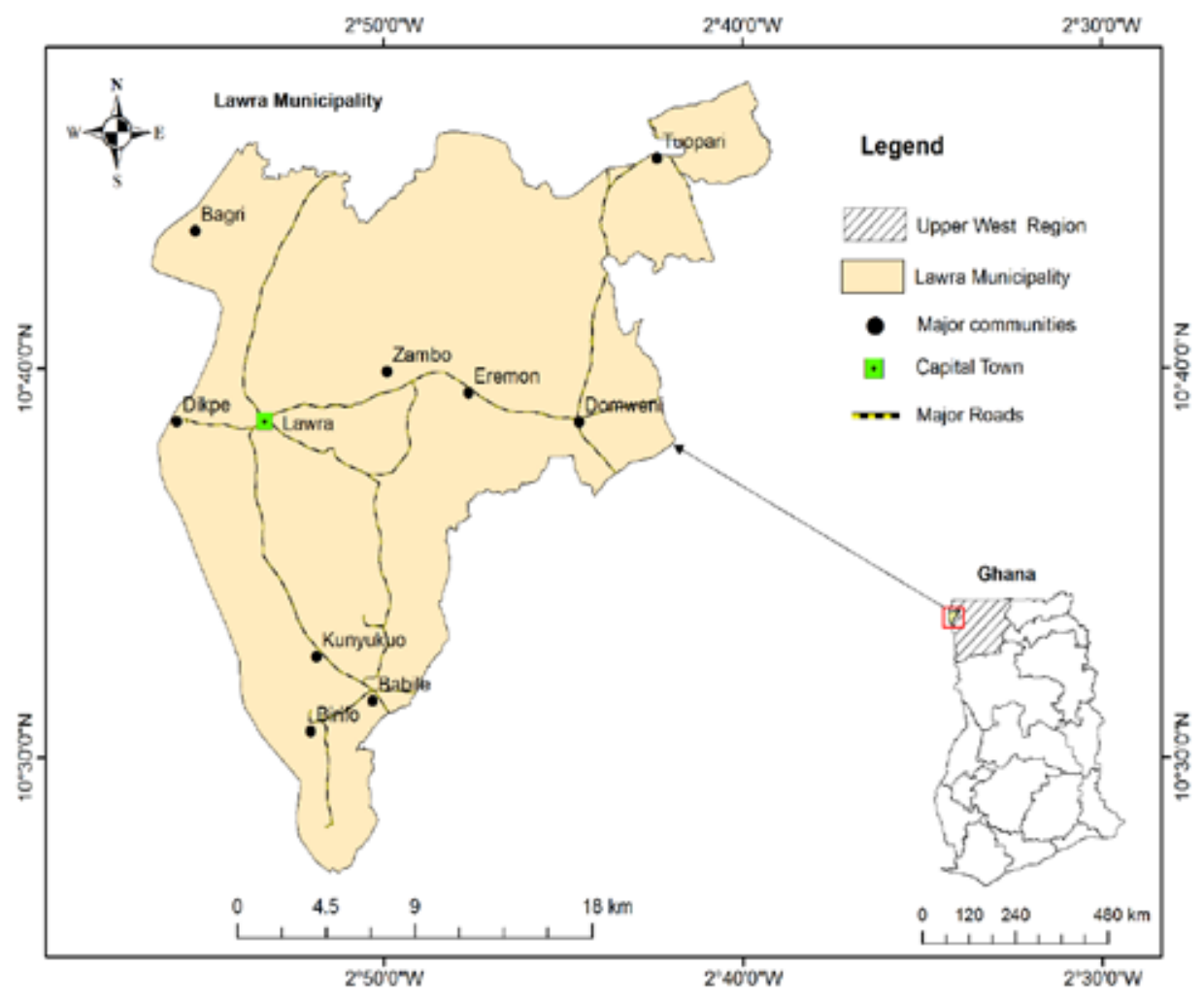

Figure 2: Map of study area in national and regional context

Source: Authors' construct, 2020.

To perform its monitoring functions effectively, the DPCU is expected to co-opt representatives from other sector agencies, persons from the private sector and civil society organisations into its activities. The DPCU is to undertake periodic project site inspections; develop indicators for assessing change and prepare progress reports and dissemination of the reports. Figure 3 shows the institutions within the decentralised planning system, the key actors, their roles and flow of information with respect to decentralised monitoring. 
Level and Information Flow Key Actors $\quad$ Roles

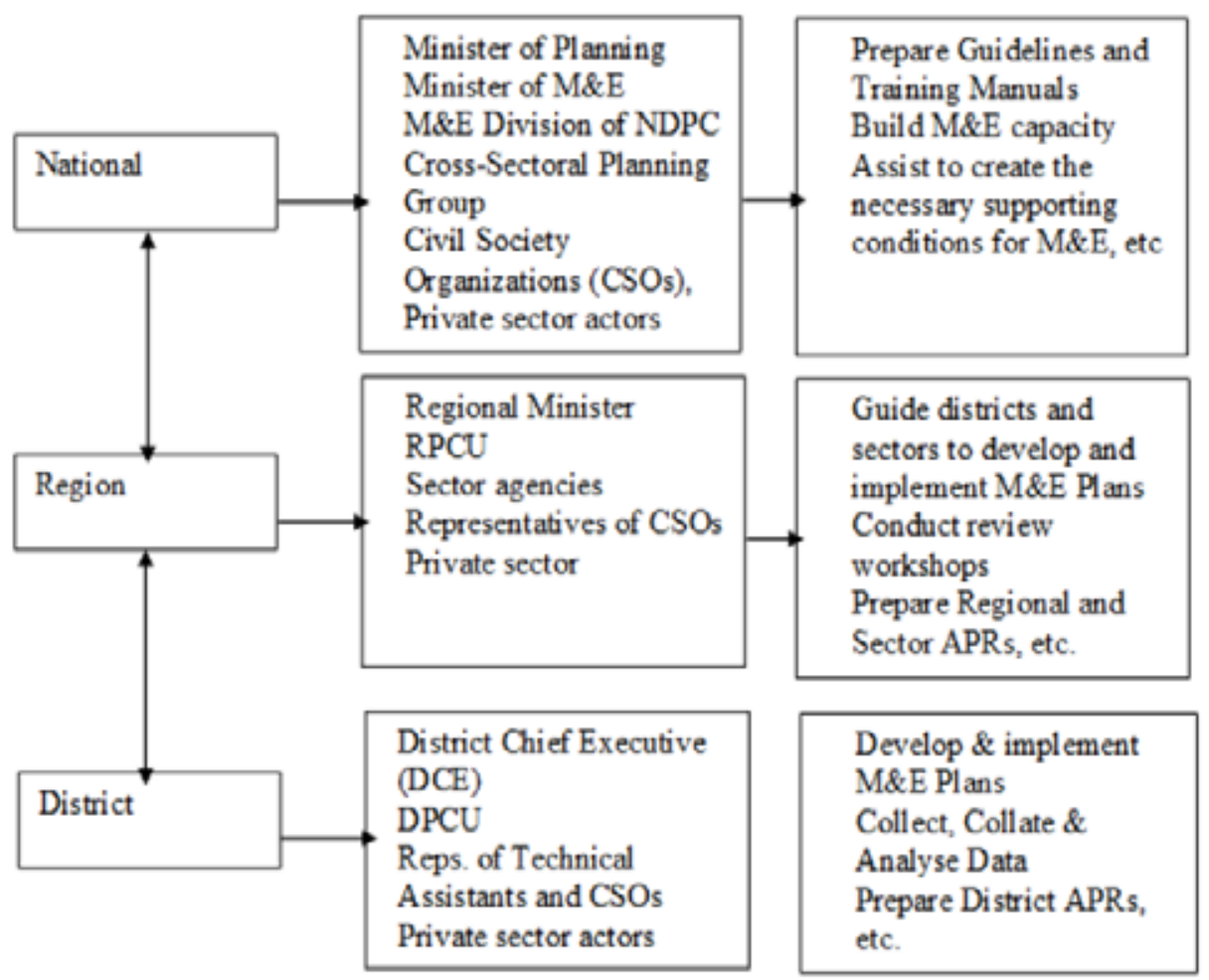

Figure 3: Decentralised monitoring institutional and reporting framework

Source: Adapted from NDPC, 2014.

Taking this context into consideration, the study examined the benefits and constraining factors of decentralised monitoring in the Lawra District of the Upper West Region. Lawra Municipality is one of the 260 districts in Ghana and one of the oldest of the eleven districts in the Upper West Region. The Upper West Region is one of three pilot regions in which decentralised monitoring and evaluation system developed by the NDPC was implemented under the DISCAP. Taking into cognisance the age of the District and its experience in the decentralised monitoring system, it was selected for the study to enable empirical lessons on the benefits and constraining factors to be analysed. The District is estimated to cover a total land area of 527 square kilometres which constitutes about $2.6 \%$ of the Region's total land area estimated to be 18,476 square km. Lawra Municipality has 29 electoral areas. The Municipality's population according to 2010 population 
and housing census stands at 54,889 with 26,346 males. It has over 88.2 percent of the inhabitants living in the rural areas. The population density of the District is 125.3 per square kilometres (GSS, 2014). The General Assembly is the highest decision making body of the Assembly and is made up of 29 elected representatives and 13 appointed members. The General Assembly has deliberative, legislative and executive functions. The District's administrative system comprises; the District Assembly, Secretariat, Departments of the District Assembly, four sub-districts; (namely, Lawra Town Council, Babile, Zambo and Eremon Area Councils) and the Unit Committees (GSS, 2014).

At the community level, there are elected members that form the unit committee and the assembly member who is also elected. There are two groups of technocrats to help in the efficient running and provision of services at the local level - those who work in the departments of the assembly (e.g. Agriculture, Health, Education etc) and those working in the district administration consisting of staff of the planning coordinating unit, budget unit, administrative unit, finance unit, internal audit and human resource unit. The process of systematically meeting the development aspirations of the people of the Assembly include; constitution of a plan preparation team, that is, the DPCU; performance review of the previous plan; data collection, collation and analysis with stakeholders at community, area/town council and decentralised departments levels; public hearings to present the current situation and ascertain development priorities; drafting of a plan consisting of policies, programmes and projects; second public hearings to review development proposals and strategies; submission of draft plan to the Regional Coordinating Councils (RCC) and National Development Planning Commission (NDPC) for vetting; review of draft District Medium Term Development Plan (DMTDP) based on comments from the RCC and NDPC and approval of plan by General Assembly. Implementation of projects is undertaken by the department of the district assembly responsible for the project (e.g. health department or agriculture department). In most cases especially infrastructure projects, project execution is contracted out to a private service provider or contractor while the implementing department in collaboration with the district assembly administration section as well as community level stakeholders as the unit committees and assembly members monitor and supervise project execution. The District has a monitoring team made up of members of the DPCU who have overall responsibility for monitoring in the District. 


\section{Methods}

A case study design was adopted for the study. Case study design focuses on few participants in order to explore comprehensively, holistically and deeply into a given complex phenomenon usually from the perspective of the participants in the study (Creswell, 2014; Flyvbjerg, 2011; Harrison, Birks, Franklin \& Mills, 2017; Yin, 2014). Respondents of the study were ten members of the Municipal Assembly Monitoring Team, one member of the Regional Economic Planning Unit and one member of staff of the M\&E division of NDPC who were all purposively selected because they all played key roles in decentralised monitoring and thus qualified to provide deep insight into monitoring at the decentralised level of governance. Key informant interviews were conducted to collect qualitative data on the benefits as well as the constraining factors of decentralised monitoring. Thematic analysis involving compiling, disassembling, reassembling, interpreting, and concluding (Castleberry \& Nolen, 2018) was used to analyse the data.

\section{RESULTS AND DISCUSSION}

This section presents the results according to the objectives of the study and the themes that emerged from the analysis. Data on the demographic profile as well as the respondents' knowledge of the decentralised monitoring guideline are first presented. This is followed by the results on the benefits and constraining factors of decentralised monitoring. The discussion section interprets the results in the light of the prevailing literature as well as their implications for the policy and practice of decentralised monitoring. Males formed $91 \%$ of respondents. All respondents attained tertiary level education and had knowledge on the decentralised monitoring guideline. They were therefore well placed to provide insight into the monitoring process of the District.

\section{Benefits of Decentralised Monitoring}

The following benefits of decentralised monitoring emerged from the analysis: projects are delivered on time and according to specification; checking the deviant behaviour of service providers; lesson learning to guide the implementation of similar projects; and gives opportunity to stakeholders to express their views on the work of local authorities. Findings from the study indicate that monitoring assisted in the timely completion and delivery of projects according to specifications as well as checking the deviant behaviour of service providers. This is conveyed by a key respondent in the following and corroborated by the other key respondents: 
"the quarterly monitoring of projects made it possible to assess progress of work and also to make sure that time and specifications of project activities are followed accordingly by the implementers" (Interview with a Key Informant, Lawra, July, 2018). The respondent added that through monitoring:

the Assembly was able to detect and correct noncompliance of a contractor constructing a 6-unit classroom block in one of the communities. The contractor had reduced the number of pillars by two, which was detected in one of the monitoring visits and he was made to rectify the anomaly at his own cost before proceeding with the project.

In a similar incident involving dishonesty by a contractor, a respondent recalled an experience in the following on his response to a question on local people involvement in monitoring activities:

A monitoring visit by the Municipal Chief Executive to a KVIP construction site saved the Assembly some money. It was reported to him and confirmed by his observation that some of the materials used were of lower cost and inferior in quality compared to what was stated in the Bill of Quantities (BOQ). The contractor was asked to pay the difference to the Assembly and that saved the Assembly money (Interview with Key respondent, Lawra, July 2018).

Monitoring helped to reduce cost overruns which have become the practice with most public funded projects; usually as result of delays in implementation resulting from late release of funds for project by government or the assembly. Because of this trend in the country, some contractors consciously delay project implementation so us to call for the revaluation of contracts. It was revealed that monitoring helped to expose such contractors and thus save the Assembly significant financial resources. These observations are generally in line with the purpose and objectives of monitoring of development activities as noted by Waithera \& Wanyoike (2015), Massuanganhe (2005) and Matsiliza (2012). These observations affirm the need for intensified monitoring as a compliment to provisions and specifications inherent in contract documents as such provisions alone are not adequate in scrutinising the aberrant behaviour of service providers.

Learning for improved service delivery: Another key observation that emerged in the study is that, decentralised monitoring helps in the identification of pitfalls in the design and implementation of projects which is then used to guide the 
design and implementation of subsequent projects. This revelation confirms the expectations of DISCAP (2004), NDPC (2014), IFRC (2011), Gudda (2011) and Carvil and Sohail (2007), cited in Mohamednoor (2017) of decentralised monitoring. Sometimes, the Assembly learned its lessons painfully as recounted by a key respondent in the following:

A CHPs Compound constructed in Tuori developed cracks two years after handing over because of inadequate logistics to undertake regular monitoring. Similarly, a story building in town had leakages, poor window fittings and faded painting less than three years after handing over. This cost the Assembly some money to fix the defects. Learning from these experiences, the Assembly began to give due consideration to implementation monitoring (Interview with Key respond, Lawra, July, 2018).

Thus, to minimise the learning of painful lessons by MMDAs, there should be a conscious effort to develop a culture of learning in organisations to ensure continuous generation of lessons and feedbacks into the planning process to enhance the quality of service delivery. The study revealed that monitoring gives opportunity to stakeholders to express their views from the project start to its completion. A remark by a Key Informant showed how decentralised monitoring creates a platform for community members to air their views on project delivery, thus, enabling downward accountability to beneficiaries on the part of service providers:

During a monitoring visit to Eremon to inspect the construction of a 12 seater KVIP, the community complained about sub-standard materials being used in executing the project. The contractor decided to use ordinary stones instead of quarry chippings to do the concrete work and it was brought to the Assembly's notice during one of their monitoring visit. Similarly, a three-unit classroom block in Dazuri where the floors were poorly done, the community complained to the contractor but this was ignored, they went ahead to complain to the consultant during a monitoring visit who later got the defect corrected (Interview with a Key Informant on July, 2018).

The narratives above illustrate how monitoring serves as avenues for beneficiaries of projects to raise concerns on the quality of project implementation. A key 
respondent remarked in the following on the benefits of engaging local people during monitoring routines: 'asking local people about their opinion on projects implemented in their communities has revealed very insightful information for the monitoring team to be able to assess the project implementers well' (Interview with a Key Informant, Lawra, July, 2018).

Local community members employed as labourers at project sites became informants on the quality of work of service providers. Community members, conscious of their stake in the quality of project implementation, observed practices that were inimical to the quality of projects and reported to the relevant authorities. This ensured quality delivery of projects. This shows that if a conscious effort is made to actively involve local people in the monitoring process, greater benefits could be realised. Active community involvement in the decentralised monitoring process should therefore be treated as a necessity if decentralised monitoring is to make a difference in the lives of citizens. The observed benefits are largely in conformity with benefits of decentralised monitoring presented in the conceptual framework.

\section{Factors Affecting Decentralised Monitoring}

The conceptual framework presents socio-political, policy, organisational and human resource factors as factors that constrain or enable decentralised monitoring. In this study, the socio-political factors did not emerge strongly as factors constraining decentralised monitoring even though, they played an undercurrent role on the issues in the organisational and policy factors. On the policy factors, the study revealed the frequent transfer of staff by the local government service as a constraint to the implementation of decentralised monitoring in the District. On the issue of frequent staff transfer, a respondent had this to said: "In less than two years, the Municipality had four different Municipal Coordinating Directors, two Municipal Planning Officers and three Municipal Budget Officers as well as the Municipal Works Engineer" (Interview with a Key Informant, July, 2018, Lawra). This frequent staff transfer affects the progress of monitoring activities. This is because, it takes time for new staff to adapt to new contexts or environments. Besides, the frequent changing of staff affects institutional memory, continuity and project implementation in general. The practice of awarding contracts at the national level emerged as a policy issue that constrains the effectiveness of monitoring at the district level. It was revealed that the phenomenon of awarding contracts for services meant for district level at the central level affects effective monitoring of such projects, because the contract specifications of such projects are 
not known to the district monitoring team. Besides, service providers implementing such projects are not accountable to the district level stakeholders. Weak coordination among agencies is noted as a challenge to monitoring implementation. It was observed that there was a belief among respondents that, such contracts have some political influence and therefore team members have to be careful on how far they can go with the monitoring of such projects. When the monitoring team members entertain fear in the discharge of their work, the quality and outcomes of the monitoring process become affected. In a political economy where so much power is vested in the executive and by extension regional ministers and MMDA chief executives, there is the need to find innovative ways of insulating monitoring team members from victimisation, if the quality of their work is to be assured. Just merely relying on the confidence, morality and integrity of team members would not be enough to achieve effectiveness in monitoring. The discussion on the policy level factors shows that, policy level issues should not be limited to monitoring guidelines to regulate the practice as portrayed in the conceptual framework. Policy factors should encompass issues of institutional coordination and collaboration in order to provide a congenial environment for decentralised monitoring.

On the organisational level constraints to decentralised monitoring, logistics for monitoring emerged as a key constraint to decentralised monitoring. Monitoring requires logistics in order to be undertaken effectively, hence, as part of the monitoring process, assessment of capacities and conditions is a main step of the decentralised monitoring process (NDPC, 2014). It merged that inadequate logistics is a challenge to the implementation of decentralised monitoring. To undertake effective monitoring, some logistics including computers, notebooks, pens, cameras, vehicles, fieldwork allowance and fuel among others are required. A respondent indicated the following as his response to the logistics situation of the Assembly for monitoring:

The Assembly has two serviceable vehicles which are used by the Municipal Chief Executive and the Municipal Coordinating Director. Whenever these two officers are out of the office on different assignments, officers (MPCU members) cannot visit project sites to inspect progress of work (Interview with Key respondent, Lawra, July, 2018).

Regarding the state of funding for monitoring activities, another key respondent said: "sometimes money to fuel the vehicle is a challenge as a result of the Assembly's over dependence on central government for funding which sometimes comes late or 
may not come at all" (Interview Key respondent, Lawra, July, 2018). The challenge with funding for monitoring corroborates the observation made by Callistus and Clinton (2016) that limited funding and difficulty accessing funds are problems affecting monitoring at the district level. The challenge with transportation is a major setback to monitoring activities because, while some officers were ready to use their personal computers for office work, none was ready to use their personal car for projects monitoring. The net result of this is that, projects under District Assembly Common Fund (DACF) suffer from irregular monitoring because of the delays in its release as well as some statutory deductions at the national level that leave only limited funds for the payment of service providers and for monitoring. Funding for decentralised monitoring except for donor driven projects has been a problem which needs to be addressed comprehensively. As noted in earlier studies (see Jili \& Mthethwa, 2016; Mark, 2007), monitoring is often undertaken after other activities mainly physical projects have been paid for. Thus in socio-political contexts where general funding for development activities is low compared to the developmental needs, leaving monitoring funding to the normal processes of the MMDAs will amount to not implementing monitoring effectively. The study also found low prioritisation of monitoring as an organisational factor that constrains the implementation of decentralised monitoring. A key respondent said this on prioritisation of monitoring. "Servicing the chief executive's car is more important than using the money for monitoring" (Interview with Key Respondent, Lawra, July, 2018). This finding is in tandem with Lahey (2015) who found priority on project launching and commissioning more important than monitoring. The poor attention to monitoring poses serious challenges to quality of services. Nonadherence to monitoring plan and calendar was identified as an organisational factor that constrained monitoring as indicated by a respondent:

During the quarterly monitoring, some key stakeholders are supposed to be part of the monitoring exercises, however, that is not always the case. Sometimes, stakeholders were given short notice to monitoring activities making it impossible for them to take part. Other times, changes are made to the monitoring calendar without communicating to the stakeholders. These practices affect the quality of the monitoring process (Interview with key respondent, Lawra, July 2018).

The decentralised monitoring process like any project intervention should be implemented as an integrated whole to yield maximum benefits. Thus, disruptions to the monitoring calendar and plan affects the quality of project delivery. This is 
because, scheduling of monitoring activities have an inherent logic which should be respected. The organisational constraining factors observed by the study, with the exception of noncompliance to monitoring calendar and plan, were largely in tandem with the conceptual framework of the study.

On the human resource constraining factors, it emerged that there was weak capacity of the MPCU to deal effectively with monitoring issues. A respondent had this to say on human resource capacity for monitoring in the District. "I have only one assistant and this is not adequate per the job expected from my department" (interview with key respondent, Lawra, July, 2018). On the adequacy of staffing for monitoring, another respondent said:

Departments who do not have adequate number of staff sometimes absent or delegate during MPCU meetings. Many a time these delegated staff may not understand or cannot contribute meaningfully in the meeting making progress slow or no progress at all (Interview with Key Informant, Lawra, July, 2018).

The response on adequacy of staff for monitoring revealed the incidence of work overload and multiple allegiance of members of the monitoring team. Though the monitoring team always draw a work plan and calendar during the planning process, some members are sometimes unable to follow the calendar because they have other schedules at the same time especially departments which are not fully decentralised or still report to their mother ministry. Again, some departments have donor projects which have different work schedules. This results in poor coordination of the implementation monitoring activities. This situation is worsened by the untimely release of funds for routine monitoring according to the monitoring plan and calendar. When the time funds are released coincide with time members of the team have different schedules to attend to, it makes their participation in monitoring irregular.

Monitoring requires specialised knowledge and skills in programme theory, logical thinking, and results oriented thinking, data collection, analysis, storage and reporting to be effective. The ability to perform once role and responsibility as an employee of an institution or organisation is dependent on how one's knowledge and skills have been enhanced by way of training. There were limited training opportunities for monitoring stakeholders to address their specific monitoring knowledge and skills gaps. On training on knowledge and skills in monitoring, a respondent said: "I have never gone for any training workshop 
since I joined the Commission and this applies to my colleagues" (Interview with a Key Informant, Accra, July, 2018). Another respondent said: "we have all been doing monitoring without going through a rigorous training programme on the design and implementation of monitoring. I believe that, if we have more of such opportunities, they would enhance our effectiveness" (Interview with Key Informant, Lawra, July, 2018). This finding is in line with Oloo (2011), Kerongo et al. (2013), Mushori (2015), Toscano (2013) and Jili and Mthethwa (2016) who found that, people tasked with monitoring activities lack access to the requisite training. The human resource factors presented in the conceptual framework were limited to knowledge, skills and attitudes of staff in relation to decentralised monitoring. This study showed that the adequacy of staff and their stability has influence on the effective implementation of decentralised monitoring.

\section{CONCLUSION AND RECOMMENDATIONS}

The study set out to contribute to the discourse on empirical benefits and constraining factors of decentralising monitoring in emerging democratic local governments. The study concludes that decentralised monitoring contributes concretely to efficient and effective service delivery as well as giving voice to community level stakeholders. It particularly contributes to checking the deviant behaviour of contractors or service providers and therefore adds to the list of benefits of decentralised monitoring. The study contributes to the need for the human resource factors in the conceptual literature not to be limited to staff adequacy, knowledge, skills and attitudes, but also stability of staff. At the policy level, the need for the creation of institutional coordination and collaboration for the creation of a conducive environment for decentralised monitoring has also been brought to the fore in the study. The study recommends investment in creating a learning culture through developing the capacity of Metropolitan, Municipal, District Chief Executives to act as champions for monitoring. In order to deal with the staffing and skills deficiencies for monitoring at the MMDA level, the local government service should ensure the recruitment of planning officers with strong monitoring background and ensure that one of the planning officers at any assembly has one monitoring specialist among them. This specialist should then form the nucleus for building monitoring capacity in the district. The knowledge, skills and attitude of the staff involved in monitoring should also be enhanced through training on the logical model, programme theory, data collection, analysis, reflection, reporting, and dissemination. MMDAs should be mandated to devote $2-5 \%$ of expenditure to monitoring as happens in many donor-driven projects in 
order to curb the funding challenge faced by decentralised monitoring stakeholders. Further studies are needed on the influence of the socio-economic and political context on the effectiveness of decentralised monitoring.

\section{REFERENCES}

Acevedo, G. L., Rivera, K., Lima, L., \& Hwang, H. (2010). Fifth Conference of the Latin America and the Caribbean Monitoring and Evaluation (M\&E) Network. Challenges in Monitoring and Evaluation: An Opportunity to Institutionalise M\&E Systems. World Bank and Inter-American Development Bank, 1-178.

African Development Bank. (2006). Monitoring and evaluation of poverty reduction strategies in regional member countries: Training needs assessment, Operations Evaluation Department (OPED)

Ahwoi, K. (2007). Monitoring and evaluation in participatory governance. Local Governance and Development Journal, 1(2), 73-84.

Akanbang, B. A. A. (2012). Process use of programme evaluation in three evaluation contexts in northern Ghana (Doctoral dissertation, University of Ghana).

Akanbang, B. A. A., Dugle, G., \& Akaateba, M. A. (2019). Q methodological study on stakeholder involvement processes that support process use of evaluation in the Upper Regions, Ghana. Legon Journal of the Humanities, 30(2), 191-214.

Akanbang, B. A. A., Yakubu, I., \& Dugle, G. (2016). Evaluation Inquiry in Donor Funded Programmes in Northern Ghana: Experiences of Pro gramme Staff. Ghana Journal of Development Studies, 13(1), 18-40.

Akanbang, B. A. A., Yakubu, I., \& Akaateba, M. A. (2015). Programme Implementers' Experiences of Evaluation Use in Northern Ghana. Annals of Humanities and Development Studies, 6(1), 38-63.

Bamberger, M. (2008). Enhancing the utilisation of evaluations for evidence-based policy making. Bridging the gap: The role of monitoring and evaluation in evidencebased policy making, 120-142.

Bamberger, M., Rugh, J., \& Mabry, L. (2011). Real world evaluation (2nd Ed). Working under budget, time, data, and political constraints: American Evaluation Association.

Callistus, T., \& Clinton, A. (2016). Evaluating barriers to effective implementation of project monitoring and evaluation in the Ghanaian construction industry. Procedia Engineering, 164, 389-394. 
Cashin, C. (2012). Comparison of the Monitoring and Evaluation Systems of the World Bank and the Global Fund.

Castleberry, A., \& Nolen, A. (2018). Methodology matters: Thematic analysis of qualitative research data: Is it as easy as it sounds? Currents in Pharmacy Teaching and Learning, 10(6), 807-815

Creswell, John W. (2014). Research design: Qualitative, quantitative and mixed methods approaches ( $4^{\text {th }}$ ed.). Thousand Oaks, CA: Sage.

DeGroff, A., \& Cargo, M. (2009). Policy implementation: Implications for evaluation. New Directions for Evaluation, 2009(124), 47-6o.

District Capacity Building Project/National Development Planning Commission. (2004). Best practices in decentralised monitoring and evaluation of poverty reduction. Report on a roundtable on emerging experiences and practices at the coconut grove regency hotel, Accra. NDPC/CIDA

Durand, K. (2004). Decentralised M\&E: Review of status of poverty exercise in three pilot districts in Northern Ghana, CIDA/MLGRD

Flyvbjerg, B. (2011). Case study (301-316). The Sage Handbook of Qualitative Research. 4th ed. Thousand Oaks, California: Sage.

Ghana Statistical Service (2014). 2010 Population and Housing Census: District Analytical Report, Lawra District.

Görgens, M., \& Zall Kusek, J. (2010). Making monitoring and evaluation systems work: A capacity development tool kit. The World Bank.

Gudda, P. (2011). A guide to project monitoring \& evaluation. AuthorHouse.

Harrison, Helena; Birks, Melanie; Franklin, Richard \& Mills, Jane (2017). Case Study Research: Foundations and Methodological Orientations. Forum Qualitative Sozialforschung / Forum: Qualitative Social Research, 18(1), Art. 19, http:// nbn-resolving.de/urn:nbn:de:0114-fqs1701195.

Holland, J., \& Ruedin, L. (2012). Monitoring and evaluating empowerment processes. Organisation for Economic Co-operation and Development (Ed.), Poverty reduction and pro-growth: The role of empowerment, 265-281.

Holvoet, N., \& Renard, R. (2006). Monitoring and evaluation under the PRSP: Solid rock or quicksand? Evaluation and Programme Planning, 30(1), 66-81.

Hughes-d'Aeth, A. (2002). Evaluation of HIV/AIDS peer education projects in Zambia. Evaluation and Programme Planning, 25(4), 397-407. 
IFAD (2008). Project level monitoring and evaluation: who really wants to know. The annual report on results and impact of IFAD operations. Office of Evaluation

International Federation of Red Cross (IFRC). (2011). Project/Programme Monitoring and Evaluation (M\&E) Guide. IFRC, Geneva.

Jackson, E. T., \& Associates Ltd (2007). District Capacity Building Project (DISCAP)

Project Completion Report, CIDA/MLGRD.

Jili, N. N., \& Mthethwa, R. M. (2016). Challenges in implementing monitoring and evaluation (M\&E): the case of the Mfolozi Municipality.

Kamau, C. G., \& Mohamed, H. B. (2015). Efficacy of monitoring and evaluation function in achieving project success in Kenya: a conceptual framework. Science Journal of Business and Management, 3(3), 82. https://doi.org/10.11648/j. sjbm.20150303.14

Kerongo, F. M., Mutua, N. M., \& Musomba, K. F. (2013). Factors Affecting the Effectiveness of Monitoring and Evaluation of Constituency Development Fund Projects in Changamwe Constituency, Kenya.

Kusters, C. (2011). Making evaluations matter: A practical guide for evaluators. Wageningen University, CDI, 2011.

Lahey, R. (2015). Common issues affecting monitoring and evaluation of large ILO projects: Strategies to address them. i-eval THINK Piece (9).

Maina, B. (2004). Monitoring and Evaluation of Support to Decentralisation and Local Governance.

Majola, M. (2014). The Implementation of the Government-wide Monitoring and Evaluation System in South Africa: A Provincial Case Study of the KwaZulu-Natal Department of Economic Development and Tourism (Doctoral dissertation, University of KwaZulu-Natal, Pietermaritzburg).

Mark, M. (2007). Monitoring and evaluation practices and challenges of Gaborone based local NGOs implementing HIV/AIDS projects in Botswana.

Mascia, M. B., Pailler, S., Thieme, M. L., Rowe, A., Bottrill, M. C., Danielsen, F., Geldmann, J., Naidoo, R., Pullin, A. S., \& Burgess, N. D. (2014). Commonalities and complementarities among approaches to conservation monitoring and evaluation. Biological Conservation, 169, 258-267.

Massuanganhe, I. J. (2005). Decentralisation and District Development. UNDP. 
Matsiliza, N. (2012). Participatory Monitoring and Evaluation: Reviewing an Inclusive Approach in the South Africa's Government Wide Monitoring and Evaluation. Africa's Public Service Delivery \& Performance Review, 1(2), 67-83.

Mohamednoor, H. (2017). Factors Influencing Monitoring and Evaluation of County Government Projects in Kenya: a Case of Road Construction Projects in Nairobi County (Doctoral dissertation, University of Nairobi).

Morris, J., \& Lawrence, A. (2010). Learning from Monitoring \& Evaluation-a blueprint for an adaptive organisation. Social \& Economic Research Group, Forest Research.

Mugambi, F., \& Kanda, E. (2013). Determinants of effective monitoring and evaluation of strategy implementation of community based projects. International Journal of Innovative Research and Development, 2(11), 67-73.

Mushori, J. (2015). Determinants of effective monitoring and evaluation of county government funded infrastructural development projects, Nakuru East Constituency, Nakuru County, Kenya. (Master's thesis University of Nairobi).

Mwangi, J. K., Nyang'wara, B. M., \& Ole Kulet, J. L. (2015). Factors affecting the effectiveness of monitoring and evaluation of constituency development fund projects in Kenya: A Case of Laikipia West Constituency. IOSR Journal of Economics and Finance (IOSR-JEF), 6(1), 2321-5925.

Nabris, K. (2002). Monitoring \& Evaluation: Based on a PASSIA Training Course. PASSIA, Palestinian Academic Society for the Study of International Affairs.

Naidoo, I. A. (2011). The role of monitoring and evaluation in promoting good governance in South Africa: A case study of the Department of Social Development. Johannesburg: University of Witwatersrand.

National Development Planning Commission (NDPC). (2014). National Monitoring and Evaluation manual. Accra

Nelson, C. (2016). Exploring Monitoring and Evaluation within a Good Governance perspective: A case study of Stellenbosch Municipality (Doctoral dissertation, Stellenbosch: Stellenbosch University).

Nyamongo, D. (2017). Factors Influencing Implementation of Monitoring and Evaluation in Water Projects in Kenya: a Case of Non-governmental Organisation Water Projects in Kajiado County (Doctoral dissertation, University of Nairobi).

Oloo, D. O. (2011). Factors affecting the effectiveness of monitoring and evaluation of constituency development fund projects in Likoni Constituency, Kenya (Doctoral dissertation, University of Nairobi, Kenya). 
Organisation for Economic Co-operation and Development (OECD). (2002). Evaluation and Aid Effectiveness, Glossary of Key Terms in Evaluation and Results Based Management.

Rajalahti, R., Woelcke, J., \& Pehu, E. (2005). Monitoring and evaluation for World Bank agricultural research and extension projects: a good practice note (Vol. 20). Agriculture \& Rural Development Department, World Bank.

Segone, M. (2008). Evidence-based policy making and the role of monitoring and evaluation within the new aid environment. The role of monitoring and evaluation in Evidence-based policy making, 16.

Sjöstedt, M. (2013). Aid effectiveness and the Paris Declaration: a mismatch between ownership and results-based management? Public Administration and Development, 33(2), 143-155. https://doi.org/10.1002/pad.1645

Tengan, C., \& Aigbavboa, C. (2016). Evaluating Barriers to Effective Implementation of Project Monitoring and Evaluation in the Ghanaian Construction Industry. Procedia Engineering, 164, 389-394. https://doi.org/10.1016/j. proeng.2016.11.635

Toscano, S. (2013). Exploring the history and challenges of Monitoring and Evaluation in international nongovernmental organisations: complemented by intern experience at Save the Children USA. Umhlaba Development Services. (2011). Introduction to Monitoring and Evaluation Using the Logical FrameworkApproach. Johannesburg, South Africa.

Waithera, S. L., \& Wanyoike, D. M. (2015). Influence of project monitoring and evaluation on performance of youth funded agribusiness projects in Bahati Sub-County, Nakuru, Kenya. International Journal of Economics, Commerce and Management, 3(11), 375.

Weyrauch, V., \& Langou, G. D. (2011). Sound expectations: from impact evaluations to policy change. International Initiative for Impact Evaluation Working Paper, 12.

World Health Organisation. (2006). Case study: country-enhanced monitoring and evaluation for antiretroviral therapy scale-up: analysis and use of strategic information in Botswana.

Yin, Robert K. (2014). Case study research: Design and methods. Los Angeles, CA: Sage.

Zall Kusek, J., \& Rist, R. (2004). Ten steps to a results-based monitoring and evaluation system: a handbook for development practitioners. The World Bank. 